\title{
ENRAIZAMENTO DE ESTACAS SEMILENHOSAS DE OLIVEIRA SOB EFEITO DE DIFERENTES ÉPOCAS, SUBSTRATOS E CONCENTRAÇÕES DE ÁCIDO INDOLBUTÍRICO ${ }^{1}$
}

\author{
ADELSON FRANCISCO DE OLIVEIRA ${ }^{2}$ \\ MOACIR PASQUAL ${ }^{3}$ \\ NILTON NAGIB JORGE CHALFUN ${ }^{3}$ \\ MURILLO DE ALBUQUERQUE REGINA ${ }^{2}$ \\ CARMEN DEL RIO RINCÓN ${ }^{4}$
}

\begin{abstract}
RESUMO - Com o objetivo de avaliar o enraizamento de estacas semilenhosas de oliveira (Olea europaea L.), sob efeito de diferentes épocas, substratos e concentrações de ácido indolbutírico (AIB), foram conduzidos na Fazenda Experimental da EPAMIG em Maria da Fé, MG, dois experimentos, sob condições de casa-devegetação rústica. As estacas foram coletadas da cultivar Ascolano 315, e os experimentos instalados nos meses de fevereiro de $2000(09 / 02)$ e abril de 2000 (27/04). O delineamento experimental utilizado foi o de
\end{abstract}

blocos casualizados em esquema fatorial 4 x 4, compreendendo, respectivamente, quatro substratos: areia, vermiculita, areia/terra $1 / 1(\mathrm{v} / \mathrm{v})$ e terra, e quatro concentrações: $0,1.000,3.000$ e $5.000 \mathrm{mg} . \mathrm{L}^{-1}$ de AIB, com quatro repetições. Pelos resultados, observa-se que é possível o enraizamento de estacas dessa espécie em instalações rústicas, obtendo-se 48,44\% de enraizamento no substrato areia/terra $1: 1(\mathrm{v} / \mathrm{v})$ e $44,28 \%$ quando utilizou-se o tratamento com AIB na concentração de $3.000 \mathrm{mg} . \mathrm{L}^{-1}$ de estacas coletadas em fevereiro 2000.

TERMOS PARA INDEXAÇÃO: Olea europaea, propagação, estaquia, substrato, AIB.

\section{ROOTINGS OF SEMI-WOODY CUTTINGS OF OLIVE TREE UNDER EFFECTS OF COLLECTION TIME, SUBSTRATE, AND CONCENTRATIONS OF INDOL-3-BUTIRIC ACID (IBA)}

\begin{abstract}
Aiming to evaluate the rooting of semiwoody cuttings of olive tree (Olea europaea L.) under effect of combinations of different times, substrates, and concentrations of indol-3-butiric acid (IBA), two experiments, under greenhouse conditions, were carried out on the EPAMIG experimental farm at Maria da Fé, State of Minas Gerais, Brazil. The cuttings were collected from the cultivar 'Ascolano 315', on the same day of the experiment installation, March $2^{\text {nd }}, 2000$ and April $27^{\text {th }}, 2000$. The experimental design used in the
\end{abstract}

two experiments was randomized blocks in $4 \times 4$ factorial scheme with four substrates (sand, vermiculite, sand/earth 1/1, and earth) and four concentrations of IBA $\left(0,1000,3000\right.$, and $\left.5000 \mathrm{mg} \mathrm{L}^{-1}\right)$, with four replicates. The results indicate rooting of this species is possible in rustic facilities, obtaining $48 \%$ of rooting for the substrate sand/earth 1:1 (v/v , and $44 \%$ when treated with IBA at the concentration of 3000 $\mathrm{mg} \mathrm{L}^{-1}$, for cuttings collected on February $9^{\text {th }}, 2000$.

INDEX TERMS: Olea europaea, propagation, cuttings, substrate, IBA.

1. Parte da tese de doutorado do primeiro autor apresentada à UNIVERSIDADE FEDERAL DE LAVRAS/UFLA, Caixa Postal 37 - 37200-000 - Lavras, MG.

2. Pesquisador da Empresa de Pesquisa Agropecuária de Minas Gerais/EPAMIG, Centro Tecnológico Sul de Minas, Caixa Postal 176, 37200.000 - Lavras, MG.

3. Professor do Departamento de Agricultura da UFLA.

4. Pesquisadora do Centro de Investigación y Formación Agraria 'Alameda del Obispo' de Cordoba, Apartado de Correos 3092, 14080, Cordoba, Espanha. 


\section{INTRODUÇÃO}

A estaquia é o método mais utilizado na propagação da oliveira (Olea europaea., Oleaceae). Entretanto, o sistema tradicional de propagação, ou seja, com estacas lenhosas de $60 \mathrm{~cm}$ enraizadas diretamente na área de plantio, apresenta além de outros inconvenientes, a necessidade de muito material vegetal (Caballero \& del Rio, 1994, 1998).

A utilização de estacas semilenhosas pode suprir essa inconveniência, mas nessa condição apresenta uma maior dificuldade de enraizamento, o que pode ser solucionado com reguladores de crescimento.

O enraizamento de estacas semilenhosas varia entre cultivares (Abazi, 2000). Em oliveira, a auxina é um fator limitante para o enraizamento (del Rio et al., 1986), sendo o ácido indolbutírico a auxina sintética mais utilizada. $\mathrm{O}$ tratamento realiza-se normalmente por cinco segundos, na base da estaca, com uma solução hidroalcoólica com AIB na concentração de 2.000 a 4.000 mg.L ${ }^{-1}$ (Nahlawi et al., 1975; Bartolini et al., 1977; Daoud et al. 1989; Caballero \& del Rio, 1994; Canözer \& Özahçi, 1994).

A concentração de hidratos de carbono nas plantas matrizes de onde são coletadas as estacas é outro fator que tem importância na formação do novo sistema radicular, e em oliveira a presença de folhas e gemas nessas estacas favorece o processo de iniciação e crescimento de raízes (Fontanazza \& Rugini, 1977; Avidan \& Lavee, 1978; Caballero \& Nahlawi, 1979).

A manutenção de estacas com e sem frutos em uma atmosfera enriquecida com $\mathrm{CO}_{2}$ permitiu provar que durante o processo de enraizamento estabelece-se entre os frutos e a base das estacas uma forte competição por assimilados disponíveis, originando-se nas ditas bases um empobrecimento de hidratos de carbono, que anula sua capacidade de enraizar (Rallo \& del Rio, 1990; del Rio, 1988; del Rio \& Proubi, 1999), significando que em períodos de florescimento ou frutificação da planta-matriz não se deve coletar estacas para propagação.

Fatores externos ao material vegetal também influenciam no enraizamento. Para alguns autores, a melhor época de preparo das estacas está relacionada com o estado fenológico da planta-matriz (Panelli et al., 1980; Fontanazza \& Rugini, 1981; Panelli et al., 1983; del Rio e Caballero, 1991). Segundo Caballero (1981), as melhores épocas são aquelas que coincidem com o final do fluxo de crescimento anual, pois as folhas estando com o máximo de sua expansão são mais eficien- tes na utilização da luz, e também no aporte de compostos necessários para o inicio da emissão de raízes.

O substrato para enraizamento deve ser limpo, livre de plantas daninhas e suficientemente firme e denso para manter as estacas em seu lugar durante o tempo de enraizamento (Proubi, 1998). Vários substratos foram provados, como, por exemplo, turfa, perlita, vermiculita ou mesclas dos mesmos, dos quais os melhores resultados foram obtidos com perlita e vermiculita $(\mathrm{Ca}-$ ballero, 1981; Nahlawi et al., 1975). Também é possível usar areia lavada, embora tenha o inconveniente de produzir um sistema radicular de maior comprimento, não ramificado e mais frágil (Hartman \& Kester, 1980). A temperatura do substrato na região de formação de raízes deve-se manter entre $20^{\circ} \mathrm{C}$ a $24^{\circ} \mathrm{C}$, o que se consegue com passagem de tubos com água quente, mantendo o intervalo de temperatura com um termostato $(\mathrm{Ca}-$ ballero, 1981).

$\mathrm{O}$ ambiente em torno das estacas deve ser muito úmido, de $80 \%$ a $90 \%$, e com temperatura amena, o que se consegue mediante uso de nebulização intermitente (Proubi, 1998). A elevada umidade que se obtém, em câmara de nebulização, mantém vivas as estacas até que se enraízem, já que faz baixar a temperatura e a transpiração da folha em razão de uma película de água que se forma em torno da mesma (Hartman \& Kester, 1980; Rallo \& del Rio, 1990).

O enraizamento de estacas semilenhosas em câmara de nebulização possibilitou notáveis avanços na propagação de inúmeras espécies vegetais, inclusive para oliveira; entretanto, um inconveniente é o alto custo financeiro para construção das instalações e também a necessidade de pessoal com algum treinamento, para manejo e condução da câmara de nebulização e manutenção inicial das plantas.

Dessa forma, o presente trabalho foi conduzido com o objetivo de estudar o enraizamento de estacas semilenhosas da cultivar de oliveira 'Ascolano 315' em diferentes substratos e doses de AIB, em duas épocas e acondicionadas em casa-de-vegetação rústica.

\section{MATERIAL E MÉTODOS}

Os experimentos foram instalados na Fazenda Experimental da EPAMIG em Maria da Fé, MG, em fevereiro de 2000 (09/02) e abril de 2000 (27/04), fim do período de chuvas e inicio do de secas na região. Foram instalados em casa rústica, nas dimensões de $4 \mathrm{~m} \mathrm{x} 4 \mathrm{~m}$ x 2,5 m de altura, cobertas com telhas tipo francesas, sendo suas laterais protegidas com filme plástico transparente, e irrigando-se internamente durante três minu- 
tos com microaspersores, uma vez à noite e duas vezes durante o dia.

Foram utilizadas estacas semilenhosas da região mediana do ramo, coletadas da cultivar 'Ascolano 315', cultivada sob condições técnicas normalmente recomendadas para a cultura no banco de germoplasma da EPAMIG em Maria da Fé, com produções anuais regulares e cujos frutos são mais utilizados para consumo em mesa.

Utilizou-se delineamento experimental blocos casualizados em fatorial $4 \times 4$, com quatro repetições, compreendendo quatro substratos: areia, vermiculita, areia/terra $1 / 1(\mathrm{v} / \mathrm{v})$ e terra, e quatro concentrações de AIB: 0, 1.000, 3.000 e $5.000 \mathrm{mg} . \mathrm{L}^{-1}$.

As parcelas experimentais foram constituídas de três vasos plásticos com 1,2 litro de substrato, onde foram plantadas quatro estacas de $12 \mathrm{~cm}$ de comprimento, com quatro folhas.

O tratamento com AIB foi realizado antes da instalação dos experimentos, submergindo durante cinco segundos a base das estacas aproximadamente $2,5 \mathrm{~cm}$ em solução hidro-alcoólica, onde foi diluído o regulador de crescimento nas concentrações utilizadas no presente trabalho.

Aos setenta e cinco dias após a instalação, avaliaram-se porcentagem de estacas enraizadas, número médio de raízes por estaca e maior comprimento de raízes.

Os dados foram transformados para raiz quadrada de X+0,5, à exceção de porcentagem de estacas enraizadas, que foi transformada para arco seno raiz de X/100 (Banzatto \& Kronka, 1989), e analisados pelo Sistema de Análise de Variância para Dados Balanceados (Ferreira, 2000), sendo a comparação das médias feita pelo teste Scott \& Knott (1974) a 5\% de probabilidade.

\section{RESULTADOS E DISCUSSÃO}

Nas Figuras 1 e 2 estão apresentados os resultados para porcentagem de estacas enraizadas, número de raízes por estacas e maior comprimento de raízes, para o efeito da interação época $\mathrm{x}$ substratos e época $\mathrm{x}$ concentrações de AIB.

Observou-se que, no experimento instalado em fevereiro de 2000 (09/02), o substrato constituído de areia/terra 1:1 possibilitou melhores rendimentos para todas as variáveis consideradas, com $48,44 \%$ de estacas enraizadas, 8,83 raízes por estaca e comprimento médio de raízes de 9,69 $\mathrm{cm}$. Quando utilizou-se somente terra como substrato, o rendimento foi estatisticamente semelhante à mistura de areia/terra. Por outro lado, no experimento instalado em abril de 2000 (27/04), os substratos utilizados, à exceção da vermiculita, apresentaram rendimentos estatisticamente semelhantes para porcentagem de estacas enraizadas e maior comprimento de raízes. Para número de raízes por estaca, a areia possibilitou melhor rendimento, 6,24 raízes por estaca (Figura $1)$.

Observa-se também, na Figura 1, que nas duas épocas de instalação dos ensaios, a vermiculita possibilitou os menores rendimentos: $10,42 \%$ e $3,12 \%$, para porcentagem de estacas enraizadas; 2,23 e 0,73 raízes por estaca e 2,69 e 0,88 cm, para o comprimento de raízes.

Além da sustentação das estacas, o substrato influencia na disponibilidade de água e oxigênio no meio para enraizamento, exercendo efeito positivo no processo fisiológico do enraizamento. Essa condição ficou evidenciada, pois melhores resultados foram verificados quando utilizou-se o substrato com maior capacidade de retenção d'água, mas também com suficiente porosidade para ocorrência de uma boa drenagem.

Quanto ao efeito de concentrações de AIB, observou-se, no ensaio instalado em fevereiro de 2000 (09/02), que não foram detectadas diferenças estatísticas para as médias obtidas com $1.000,3.000$ e 5.000 mg.L ${ }^{-1}$ do regulador de crescimento, com 34,39\%, 44,28\% e $38,03 \%$ de estacas enraizadas e $8,00,9,56$ e 7,69 cm para maior comprimento de raízes, respectivamente. Nesse ensaio, para número de raízes por estaca, observou-se que doses maiores de AIB proporcionaram maior número de raízes: 4,96 raízes por estaca para $1.000 \mathrm{mg} . \mathrm{L}^{-1}$, 8,12 raízes por estaca para $3.000 \mathrm{mg} \cdot \mathrm{L}^{-1}$ e 11,68 raízes por estaca para $5.000 \mathrm{mg} . \mathrm{L}^{-1}$ (Figura 2).

Para o ensaio instalado em abril de 2000 (27/04), melhores porcentagens de enraizamento foram obtidas com as doses de 3.000 e 5.000 mg. $\mathrm{L}^{-1}$ de AIB, $16,64 \%$ e $23,93 \%$, respectivamente, sendo essas médias estatisticamente semelhantes. Resultados semelhantes foram observados para maior comprimento de raízes, com 2,94, 3,75 e 4,88 cm para $1.000,3.000$ e 5.000 mg.L ${ }^{-1}$ de AIB, respectivamente. Para número de raízes por estacas, doses de 0 e $1.000 \mathrm{mg} . \mathrm{L}^{-1}$ apresentaram resultados semelhantes, com 0,63 e 2,41 raízes por estaca ( $\mathrm{Fi}$ gura 2).

Nos dois ensaios, a testemunha (ausência de tratamento com AIB) proporcionou o menor rendimento para as três variáveis estudadas (Figura 2). 

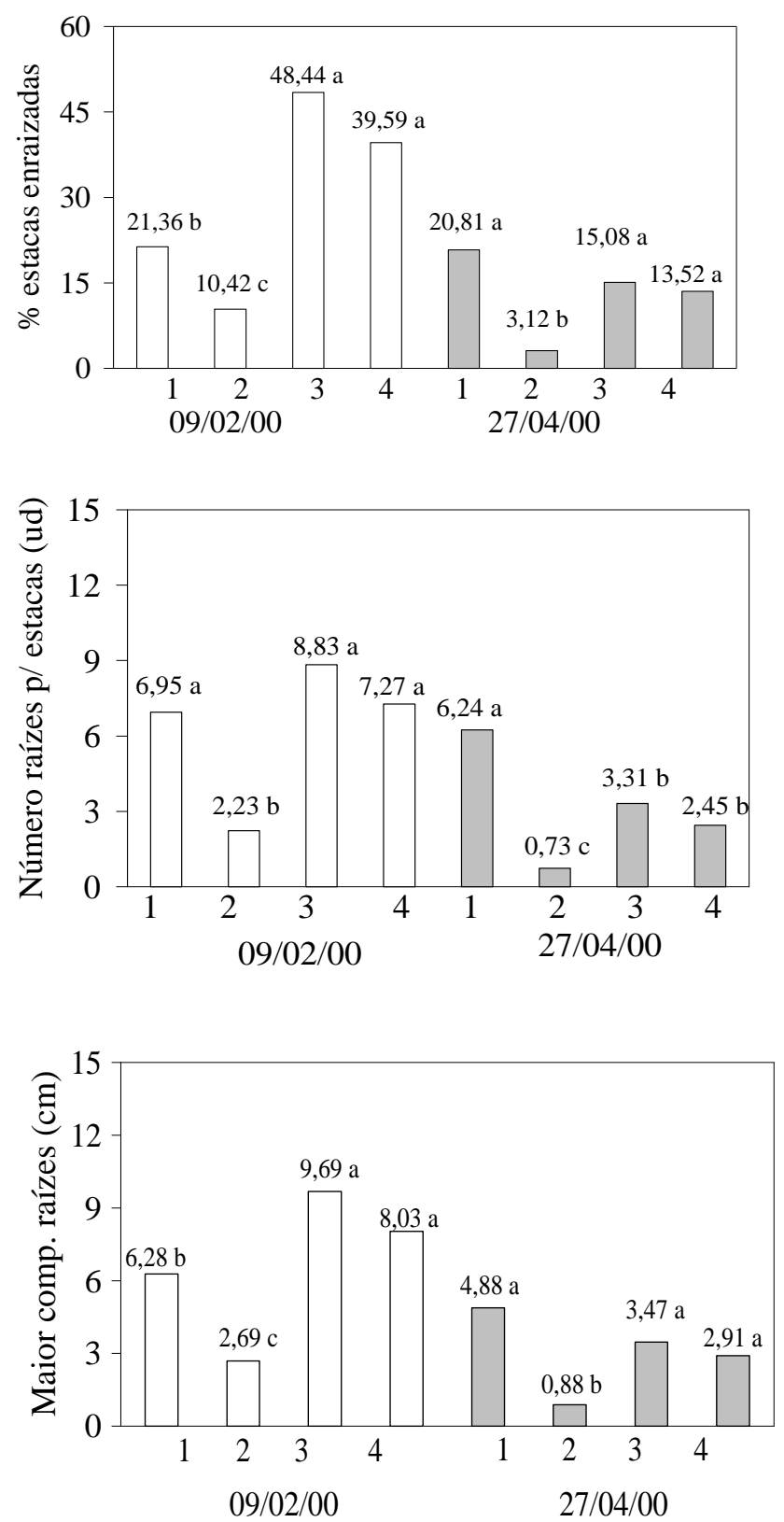

1 - areia $\quad 2$ - vermiculita $\quad 3$ - areia/terra $(1 / 1) \quad 4$ - terra

FIGURA 1 - Efeito de substratos de enraizamento em porcentagem de estacas enraizadas, número de raízes por estaca e maior comprimento de raízes de oliveira cv. 'Ascolano 315', em duas épocas de instalação de ensaios. Maria da Fé, MG, 2000.

Ciênc. agrotec., Lavras. V.27, n.1, p.117-125, jan./fev., 2003 

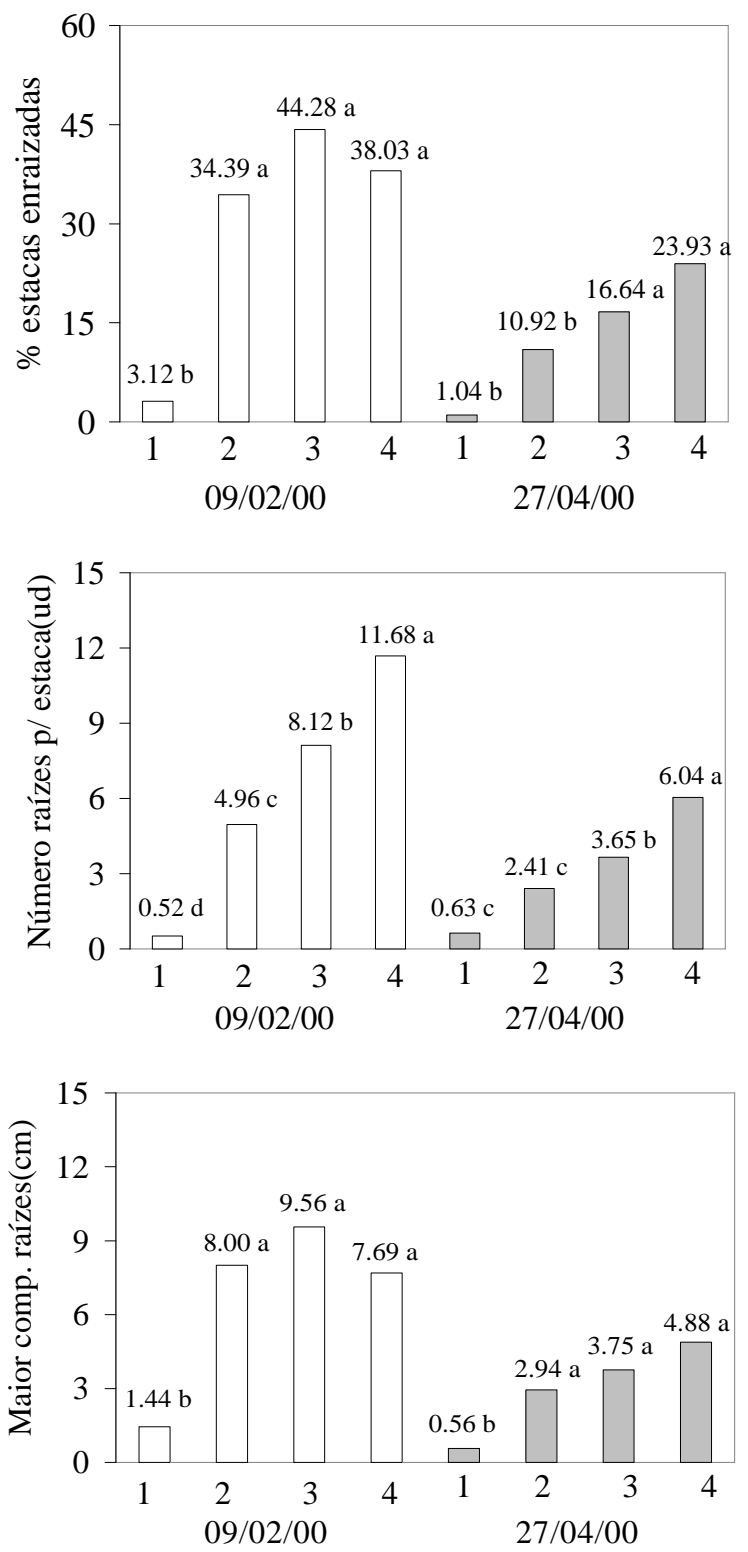

1-0 mg. $\mathrm{L}^{-1}$ AIB $\quad 2-1000 \mathrm{mg} . \mathrm{L}^{-1} \mathrm{AIB} \quad 3-3000 \mathrm{mg} \cdot \mathrm{L}^{-1} \mathrm{AIB} \quad 4-5000 \mathrm{mg} \cdot \mathrm{L}^{-1}$

FIGURA 2 - Efeito de concentrações de AIB em porcentagem de estacas enraizadas, número de raízes por estaca e maior comprimento de raízes de oliveira cv. 'Ascolano 315', em duas épocas de instalação de ensaios. Maria da Fé, MG, 2000.

Na Figura 3, estão apresentados os resultados de número de raízes por estaca, efeito da interação substratos versus concentrações de AIB. Observou-se que a concentração de $5.000 \mathrm{mg} \cdot \mathrm{L}^{-1}$ proporcionou maiores médias: 11,11 raízes por estaca para areia, $11,84 \mathrm{em}$ areia/terra 1:1 (v/v) e 8,76 ud em terra e, quando não se realizou tratamento com AIB, as médias foram mais baixas: 1,13 raiz por estaca para areia, 1,04 ud em areia/terra 1:1 (v/v) e 0,13 em terra (Figura 3). 


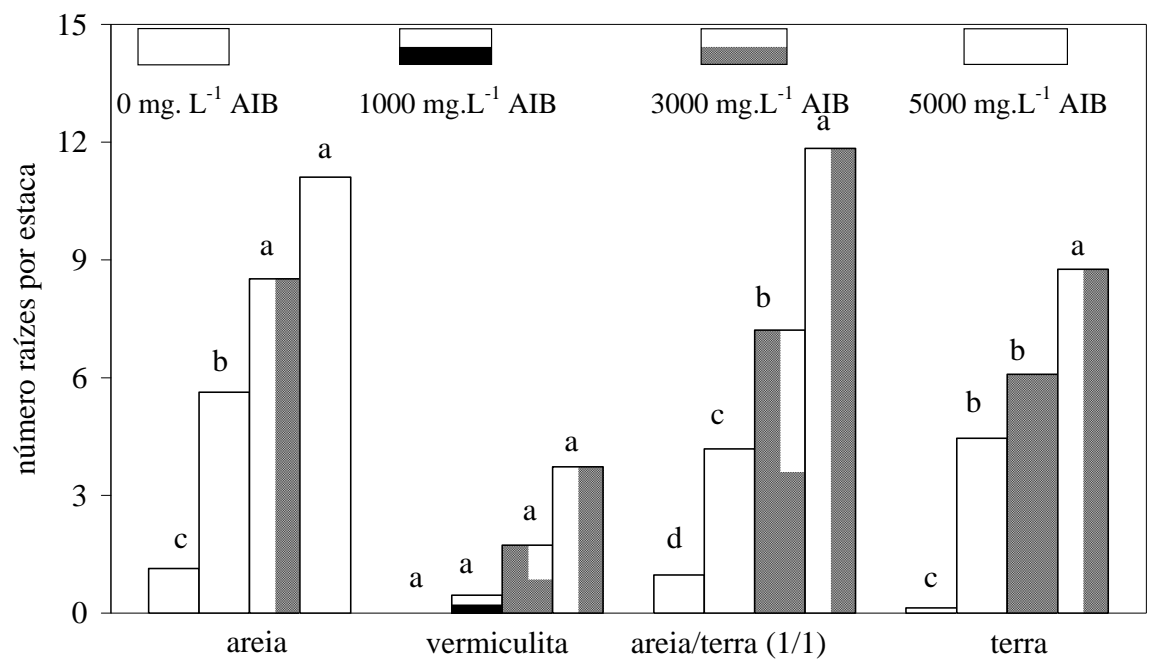

FIGURA 3 - Efeito da interação do substrato com a concentração de AIB no número de raízes por estaca. Maria da Fé, MG, 2000.

É importante ressaltar que, no substrato areia/terra 1:1 (v/v), observou-se que o número de raízes por estaca aumentou, à medida que foram utilizadas concentrações maiores de AIB: 1,04 raízes por estaca para $0 \mathrm{mg} . \mathrm{L}^{-1}, 4,18$ para $1.000 \mathrm{mg} . \mathrm{L}^{-1}, 7,21$ para 3.000 mg..$^{-1}$ e 11,84 para 5.000 mg.L ${ }^{-1}$ (Figura 3).

Quando utilizou-se a vermiculita, não foi observado efeito de doses de AIB no número de raízes por estaca, pois as médias foram estatisticamente iguais: 0,0 para $0 \mathrm{mg} . \mathrm{L}^{-1}, 0,46$ para $1.000 \mathrm{mg} . \mathrm{L}^{-1}, 1,73$ para 3.000 mg. $\mathrm{L}^{-1}$ e 3,73 para $5.000 \mathrm{mg} . \mathrm{L}^{-1}$, respectivamente (Figura 3$)$.

Na Tabela 1 estão apresentados os resultados médios das variáveis estudadas, obtidos para cada experimento, correspondendo ao fator de variação época de instalação dos ensaios. Observou-se que, no experimento instalado em fevereiro de 2000 (09/02), obtiveram-se resultados superiores para todas as características estudadas, inferindo-se que essa época foi mais favorável para o enraizamento de estacas semilenhosas dessa espécie, comparada com o experimento instalado em abril de 2000 (27/04).

$\mathrm{O}$ período em que foram instalados os experimentos correspondia ao final do ciclo de produção. Os frutos já haviam sido colhidos e a planta-matriz, provavelmente apresentava-se com baixo nível de reservas nutricionais, que foram utilizadas para sua produção, o que pode ter contribuído para a obtenção de baixos per- centuais de enraizamento. Esse estado fenológico, de acordo com estudos de diversos pesquisadores (Fontanazza \& Rugini, 1981; Pannelli et al., 1983; del Rio et al., 1986; del Rio, 1988), não corresponde à época mais favorável para a coleta e preparo de estacas para o enraizamento, o que talvez poderia explicar o baixo rendimento observado nos dois ensaios.

Observou-se, entretanto, que o primeiro experimento apresentou melhores resultados provavelmente devido ao fato de que as estacas utilizadas para sua instalação foram coletadas de plantas que apresentavam um melhor vigor vegetativo. Segundo Caballero (1981), as melhores épocas para o enraizamento de estacas de oliveira são aquelas que coincidem com o final do fluxo de crescimento anual, porque as folhas estão com o máximo de sua expansão, são mais eficientes na utilização da luz e também no aporte de compostos necessários para o início da emissão de raízes.

O período de instalação do segundo experimento coincidiu com a época de ocorrência de baixas temperaturas e também de escassez de chuvas na região de Maria da Fé. Portanto, seu baixo rendimento pode ser devido ao estado de repouso vegetativo em que se encontravam as plantas matrizes de onde foram coletadas as estacas. Dessa forma, supostamente os conteúdos internos de promotores e inibidores da iniciação de raízes apresentavam-se desfavoráveis para o enraizamento de estacas. 
TABELA 1 - Média de porcentagens de estacas enraizadas, número de raízes por estacas e maior comprimento de raízes estudadas em dois experimentos de avaliação de substratos e concentrações de AIB, no enraizamento de estacas semilenhosas de oliveira (Olea europaea), Maria da Fé, MG, 2000.

\begin{tabular}{ccc}
\hline Variáveis & $\begin{array}{c}\text { Experimento 1 } \\
\text { Fevereiro de 2000 (09/02) }\end{array}$ & $\begin{array}{c}\text { Experimento 2 } \\
\text { Abril de 2000 (27/04) }\end{array}$ \\
\hline Porcentagem estacas enraizadas & $29,85 \mathrm{~A}$ & $13,13 \mathrm{~B}$ \\
Número raízes por estacas (ud) & $6,32 \mathrm{~A}$ & $3,18 \mathrm{~B}$ \\
Maior comprimento de raízes (cm) & $6,67 \mathrm{~A}$ & $3,03 \mathrm{~B}$ \\
\hline
\end{tabular}

Médias seguidas pela mesma letra na horizontal não diferem entre si, pelo teste Scott e Knott (1974), a 5\% de probabilidade.

Finalmente, de acordo com os resultados obtidos no presente trabalho, observou-se que o substrato constituído de areia/terra $1: 1(\mathrm{v} / \mathrm{v})$ foi o que ofereceu melhores condições para o enraizamento dessa espécie. A vermiculita, no entanto, não permitiu resultados satisfatórios, o que difere de informações obtidas de outras pesquisas.

Outros autores, trabalhando com enraizamento de estacas de oliveira sob condições de câmara de nebulização intermitente e com manutenção de temperaturas controladas de ambiente e de substrato verificaram melhores resultados quando utilizou-se perlita ou mistura de perlita com vermiculita, como meios de enraizamento (Nahlawi et al., 1975; Caballero, 1981).

Também de acordo com os resultados do presente trabalho e, conforme já comprovado por alguns autores (del Rio et al., 1986; Caballero \& del Rio, 1994), observou-se que o efeito do tratamento basal das estacas com AIB foi um fator determinante no processo de enraizamento, uma vez que, com a testemunha, praticamente não houve enraizamento. Para concentração de AIB, os resultados observados são concordantes com os apresentados por alguns autores (Nahlawi et al., 1975 ; Bartolini et al., 1977; Panelli et al., 1980; Daoud et al., 1989; Canozer \& Ozahçi 1994), que indicam ser 3.000-4.000 mg.L.-1 a concentração em que se obtêm melhores resultados.

Ressalta-se que as médias gerais para porcentagem de estacas enraizadas, $29,85 \%$ no primeiro ensaio e $13,13 \%$ no segundo, são valores relativamente baixos comparados com $80 \%$ a $90 \%$ que se obtêm quando se utiliza câmara de nebulização com controles internos de ambiente (Caballero, 1981; Caballero \& del Rio, 1998). Por outro lado, é importante considerar que as instalações rústicas onde foram conduzidos os experimentos podem não ter permitido a maximização dos efeitos do tratamento com o regulador de crescimento e do melhor substrato, para o momento fenológico em que se encontrava a planta-matriz. Embora, ainda assim, seja vantajoso, considerando seu baixo custo.

\section{CONCLUSÕES}

Para as condições em que o presente trabalho foi realizado, conclui-se que e possível o enraizamento de estacas semilenhosas de oliveira da cv. Ascolano 315 utilizando-se instalações sem qualquer controle ambiental, podendo-se obter $29,85 \%$ de estacas enraizadas.

A primeira época de coleta de estacas para o enraizamento, isto é, fevereiro de 2000 (09/02), quando as plantas matrizes apresentavam maior vigor vegetativo, possibilitou melhores rendimentos em todas as variáveis, comparadas com a segunda época, abril de 2000 (27/04); sendo o substrato areia/terra 1:1 (v/v) o que permitiu maior porcentagem de estacas enraizadas, $48,44 \%$; e as concentrações de 3.000 e $5.000 \mathrm{mg} . \mathrm{L}^{-1}$ de AIB foram as que permitiram o incremento na porcentagem de estacas enraizadas, no número de raízes por estaca e no maior comprimento de raízes, podendo, assim, ser recomendada a concentração de $3.000 \mathrm{mg} . \mathrm{L}^{-1}$ de AIB, por ser mais econômica.

\section{REFERÊNCIAS BIBLIOGRÁFICAS}

ABAZI, U. Propagación de progenies de olivo por estaquillado semileñoso bajo nebulización. 2000. 87 p. Tesis (Master of Science) - Universidad de Córdoba, Córdoba.

AVIDAN, B.; LAVEE, S. Phisiological aspects of the rooting ability of olive cultivars. Acta Horticulturae, Wageningen, v. 79, p. 93-101, 1978. 
BANZATTO, D. A.; KRONKA, S. N. Experimentação agrícola. Jaboticabal: FUNEP, 1989. 247 p.

BARTOLINI, G.; FIORINO, P. ; BOUZAR, M. Research on the influence of steeping in water of cuttings. 3. effect of steeping in water with different $\mathrm{pH}$ [hydrogen-ion concentration] on the rooting of olive cuttings cv. "Frantoio". Rivista Ortoflorofruttcoltura Italiana, Firenze, v. 61, n. 6, p. 409-417, nov./dic. 1977.

CABALlERO, J. M. Multiplicación del olivo por etaquillado semileñoso bajo nebulización. Madrid: Instituto Nacional de Investigaciones Agrarias, 1981. 39 p. (Comunicaciones INIA, Serie Producción Vegetal, 31).

CABALlERO, J. M.; del RIO, C. Métodos de multiplicación, 89-113. In: BARRANCO, D. FÉRNANDEZ-ESCOBAR, R.; RALLO, L. (Ed.). El cultivo de olivo. 2. ed. Madri: Junta de Andalucia/Mundi-Prensa, 1998. $651 \mathrm{p}$.

CABAllero, J. M.; del RIO, C. Propagación del olivo por enraizamiento de estaquillas semileñosas bajo nebulización. Sevilla: Consejeria de Agricultura, Junta de Andalucia, 1994. 23 p. (Comunicación I+D Agroalimentaria, 7/1994).

CABALLERO, J. M.; NAHLAWI, N. Influence of carbohydrates and washing with water on the rooting of the Gordal cultivar of the olive (Olea europaea L.). Anais Instituto Nacional de Investigaciones Agrarias, Serie Produción Vegetal, Madrid, v. 11, p. 219-230, 1979.

CANÖZER, Ö.; ÖZAHÇI, E. Capacidad rizógena de cultivares de olivo de Turquía por estaquillado herbáceo bajo nebulización. Olivae, Madrid, v. 51, p. 29-33, apr. 1994.

DAOUD, D. A., AGHA, J.T., ABU-LEBDA, K.H.; AL-KAIAT, M.S. Efecto del AIB sobre el enraizamiento de estacas herbáceas de olivo. Olivae, Madrid, v. 27, n. 6, p. 28-30, jun. 1989.

del RIO, C. Influencia de los hidratos de carbono y de la presencia del fruto el el enraizamiento de olivo por estaquillado semileñoso. 1988.148 p. Tesis (Doctoral) - Universidad de Córdoba, Córdoba.

del RIO, C.; PROUBI, A. Training Date Affects Height of Nursery Olive (Olea europaea L) Trees.
HortTechnology, Alexandria, v. 9, n. 3, p. 482-485, 1999.

del RIO, C., CABAllero, J. M. Effects of carbohydrate content on the seasonal rooting of vegetive and reproductive cuttings of olive. Journal of Horticultural Science, Ashford, v. 66, n. 3, p. 301-309, 1991

del RIO, C., CABALLERO, J. M. RALLO, L. Influencia de las incisiones basases sobre la variación estacional del enraizamiento de estaquillas de "Picual" y Gordal sevillana”, Olea, Córdoba, v. 17, p. 27-29, 1986.

FERREIRA, D. F. Análises estatísticas por meio do Sisvar para Windows versão 4.0. In. REUNIÃO ANUAL DA REGIÃO BRASILEIRA DA SOCIEDADE INTERNACIONAL DE BIOMETRIA, 45., 2000, São Carlos. Anais... São Carlos: SIB, 2000. p. $255-258$

FONTANAZZA, G.; RUGINI, E. Effect of leaves and buds removal on rooting ability of olive tree cuttings. Olea, Córdoba, v. 2, p. 9-28, 1977.

FONTANAZZA, G.; RUGINI, E. Radicazione delle cultivar di olivo con il metodo dell "cassone riscaldato". Revista delle colture Legnose da Frutta e della Ortofloricoltura, Italy, v. 43, n. 2, p. 39-44, 1981.

HARTMAnN, H. T.; KESTER, D. E. Propagacion de plantas, principios y practicas. México: CECSA, 1980. 814 p.

NAHLAWI, N.; HUMANES, J.; PHILIPPE, J. M. Factors affecting the rooting of olive tree cuttings [Beta indolebutyric acid, growth substances]. Anais del Instituto Nacional de Investigación Agraria, [S.1.], v. 5, p. 147-166, 1975. Serie Produción Vegetal

NAHLAWI, N.; RALLO, L. CABALLERO, J. M.; EGUREN, J. The capacity of olive cultivars to root by cuttings under mist [Beta indolebutyric acid, growth substances]. Anais del Institutlo Nacional de Investigación Agraria, v. 5, p. 167-182, 1975. Serie Produción Vegetal

PANELLI, G., FILIPUCCI, B.; DADDI, P. Rizogenesi e ciclo vegetativo in Olea europaea L cv. 'Frantoio', 'Leccino' e 'Morailo'. Influenza di trattamenti com fitoreguladori basali e fogliari a diverse concentrazioni. Annali dell'Istituto Sperimentale per l'Olivicoltura, Consenza, v. 6, p. 135-150, 1980. 
PANNELLI, G.; FILIPPUCCI, B.; CASANO, F. Plant regulators and rooting environments for olive cuttings [Cultivars, Italy]. Fitoregolatori ed ambienti per la radicazione di talee semilegnose di olivo. Frutticoltura, Bologna, v. 45, n. 6/7, p. 51-56, june/july 1983.

PROUBI, A. Factores que influyen en el enraizamiento y crianza de plantas de olivo. 1998. 86 p. Tesis (Master of Science) - Universidad de Córdoba, Córdoba.
RALLO, L.; del RIO, C. Effect of a CO2 enriched enviroment on the rooting ability and carbohydrate level of olive cuttings. Advances in Horticultural Science, New York, v. 4, n. 2, p. 129130, 1990.

SCOTT, A. J.; KNOTT, M. A cluster analysis method for grouping means in the analysis of variance. Biometrics, Washington, v. 30, p. 507512, Sept. 1974. 